\title{
The use of $n$-alkanes to estimate diet composition of ruminants grazing on species diverse plant communities — Effect of feeding selectivity on diet composition estimates
}

\author{
L.M.M. Ferreira ${ }^{\mathrm{a}, *}$, M. Oliván ${ }^{\mathrm{b}}$, R. Celaya ${ }^{\mathrm{b}}$, U. Garcia ${ }^{\mathrm{b}}$, \\ M.A.M. Rodrigues ${ }^{a}$, K. Osoro ${ }^{b}$

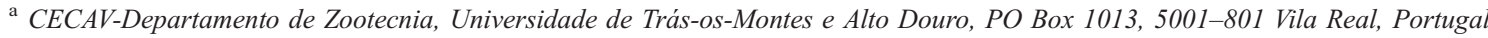 \\ b SERIDA - Servicio Regional de Investigación y Desarrollo Agroalimentario, PO Box 13, 33300 Villaviciosa, Asturias, Spain
}

Received 19 September 2006; received in revised form 13 November 2006; accepted 19 December 2006

\begin{abstract}
The present study aimed to evaluate the effect of feeding selectivity (FS) within a dietary group comprising plant species with similar alkane profile, on the estimates of diet composition of goats, sheep and cows grazing on vegetation composed of gorseheathland with areas of improved pastures. Plant species collected in the field study were grouped in four dietary groups according to cluster analysis: D1 (Lolium perenne, Pseudarrhenatherum longifolium and Agrostis capillaris), D2 (Calluna vulgaris, Erica cinerea, Erica umbellata, Erica australis), while Erica arborea (D3) and Ulex gallii (D4) remained as individual components due to their distinct $n$-alkane profiles. The application of different levels of feeding selectivity $(0,5,15,30,60,90$ and $100 \%)$ to the graminaceous species included in D1 group affected significantly $(P<0.05)$ the diet composition estimates as a result of the modification of the alkane pattern of the dietary group used in the calculations. However, this effect was not so evident within all ranges of FS and when evaluated in the heather species of D2 group. When L. perenne and C. vulgaris were removed from D1 and D2 dietary groups and treated as individual components, there was a decrease in the FS effect on the diet composition estimates. The results obtained show that dietary groups formed by multivariate statistical analysis should be used carefully as they could be sensitive to feeding selectivity, with consequently large effects on the estimates of diet composition. This effect will depend on the similarity in the alkane profile of the plant species that composed the dietary group.
\end{abstract}

(C) 2007 Elsevier B.V. All rights reserved.

Keywords: Alkanes; Feeding selectivity; Diet composition; Ruminants

\section{Introduction}

Alkanes are saturated hydrocarbons present in the cuticular waxes of most of higher plants and their profile

\footnotetext{
* Corresponding author. Tel.: +351 259350421; fax: +351 259325058

E-mail address:1mf@utad.pt (L.M.M. Ferreira).
}

is specific to plant species and plant parts (Dove et al., 1996; Ferreira et al., 2005). These "fingerprints" have already been explored with success to estimate the proportions of different plant species and/or plant parts in mixtures of ten herbage species (Hoebee et al., 1998) and from faeces of different animal species fed up to five dietary components in sheep (Lewis et al., 2003, Valiente et al., 2003, Ferreira et al., 2006), goats 
(Brosh et al., 2003, Ferreira et al., 2005), cattle (Brosh et al., 2003; Ferreira et al., in press) and equines (Ferreira et al., in press) in indoor controlled studies.

In complex vegetation communities under free range grazing conditions there are a limited number of $n$-alkanes available as markers contrasting with the extremely high number of components on offer to the animals. Although the current analytical procedures allow the identification and quantification of 16 alkanes $\left(\mathrm{C}_{21}\right.$ to $\left.\mathrm{C}_{36}\right)$, some of them present very low concentrations both in plants and in faeces (especially those with chain length lower that 25 and higher than 33 carbon atoms) which means that they are less useful as markers due to their higher potential analytical error (Brosh et al., 2003; Dove and Mayes, 2005). Consequently, the number of alkane markers available for diet composition calculations is probably limited to $9\left(\mathrm{C}_{25}\right.$ to $\left.\mathrm{C}_{33}\right)$.

Moreover, the increase of the number of diet components will likely result in less accurate diet composition estimates since there is an increasing likelihood that different combinations of two or more components have a similar alkane pattern to that of another combination of components. This could result in similar faecal alkane pattern and could reduce the precision of diet composition estimates (Dove and Mayes, 2005). To overcome these limitations three possible options to obtain estimates of diet composition are normally used: 1) the reduction of the number of plant species to be discriminated, by grouping species with indistinguishable alkane profile into dietary groups (Martins et al., 2002); 2) by the elimination of plant species based on preliminary information (observation of the animals and or data on the vegetation cover available; Dove and Mayes, 2005); 3) increasing the discriminatory power by the combination of alkanes with other methods of estimating diet composition (combination of microhistological and alkane procedures used by Salt et al., 1994), or with other markers, such as long-chain fatty alcohols (Kelman et al., 2003; Bugalho et al., 2004; Ali et al., 2004, 2005) and longchain fatty acids (Ali et al., 2004, 2005), providing a more specific "fingerprint" of each plant species.

On the other hand, Bugalho et al. (2002) pointed out that when expressing diet composition in terms of dietary groups, there is the possibility of animals selecting differently the plant species comprising the group, modifying its $n$-alkane contribution to the diet ingested. This selective behaviour could alter the contributions of the species within the dietary group into the $n$-alkane profile in faeces and may influence the accuracy of the diet composition estimate.
The objective of this work was to assess the effect of using different levels of feeding selectivity on a particular plant species within a dietary group, formed according with their similar alkane profile, on diet composition estimates. This study was carried out using a dataset of $n$-alkane pattern of herbaceous and browse species, and faeces of three species of ruminants (goats, sheep and cattle) grazing on natural vegetation communities composed of gorse-heathland with areas of ryegrass pastures.

\section{Materials and methods}

\subsection{Experimental site}

This study was carried out on an experimental plot (22 ha) located at the Carbayal Research Station (900$1000 \mathrm{~m}$ above sea level), at San Isidro's Mountain, Asturias, North-Western Spain (latitude $43^{\circ} 21^{\prime}$, longitude $-6^{\circ} 53^{\prime}$ ) in June. The vegetation of the experimental plot consisted mainly of short heathers (Erica umbellata L., Erica cinerea L. and Calluna vulgaris L.), tall heathers (Erica australis L. and Erica arborea L.) and gorse (Ulex gallii Planchon). Some herbaceous natural species, such as Pseudarrhenatherum longifolium Rouy and Agrostis capillaris L., could also be found mixed with the heather species and gorse. This natural vegetation was interspersed with patches of improved pastures of perennial ryegrass (Lolium perenne L.).

\subsection{Dataset}

The dataset consisted of the $n$-alkane pattern of the main plant species present in the plot. The samples of the vegetation components (leaves of herbaceous species and green shoots of woody species) were randomly collected in different locations.

At the same time, rectal faecal samples were collected from 7 Asturiana de los Valles cows $(622 \mathrm{~kg}$, s.d. $17.8 \mathrm{~kg}), 42$ adult non-lactating Cashmere goats (39 kg, s.d. $1.3 \mathrm{~kg}$ ) and 42 crossbreed (Gallega*Latxa) sheep $(45 \mathrm{~kg}$, s.d. $1.5 \mathrm{~kg}$ ) grazing on the experimental plot, managed in a mixed herd to have the same opportunities for diet selection.

Samples of the plant species and faeces were immediately frozen at $-20{ }^{\circ} \mathrm{C}$ and then freeze-dried and milled through a $1 \mathrm{~mm}$ screen for $n$-alkane analysis. Alkane concentration of individual samples of the plant species and faeces was analysed in duplicate according to the method of Mayes et al. (1986) modified by Oliván and Osoro (1999). 


\subsection{Calculations}

\subsubsection{Diet composition}

Individual diet composition estimates were obtained using an optimization procedure which minimises the sum of squared discrepancies between the actual $(A)$ alkane proportions in faeces (adjusted for the incomplete faecal recoveries) and the estimated $(E)$ proportions (different combinations of diet components), as follows (Salt et al., 1994; Oliván et al., 1999):

$$
\begin{aligned}
\sum_{i=1}^{n} & {[A-E]^{2} } \\
= & \sum_{i=1}^{n}\left[\frac{F i}{F t}-\frac{a^{*} \mathrm{D} 1 i+b^{*} \mathrm{D} 2 i+c^{*} \mathrm{D} 3 i+d^{*} \mathrm{D} 4 i}{a^{*} \mathrm{D} 1 t+b^{*} \mathrm{D} 2 t+c^{*} \mathrm{D} 3 t+d^{*} \mathrm{D} 4 t}\right]^{2} \text { minimal }
\end{aligned}
$$

where $a, b, c$ and $d=(1-a-b-c)$ are the proportions of components D1, D2, D3 and D4 in the diet; Fi, D1 $i$, $\mathrm{D} 2 i, \mathrm{D} 3 i$ and $\mathrm{D} 4 i$ are the concentrations of alkane $i$ in the faeces (corrected for incomplete faecal recovery) and components D1, D2, D3 and D4; Ft, D1 $t, \mathrm{D} 2 t, \mathrm{D} 3 t$ and $\mathrm{D} 4 t$ are total alkane concentrations in the faeces and components D1, D2, D3 and D4. For diet composition calculations, the dietary groups considered as possible diet components comprised plant species with similar $n$-alkane profile, according to cluster analysis results. Additionally, different combinations of the graminaceous (L. perenne, P. longifolium and A. capillaris) and heathers $(C$. vulgaris, E. cinerea, E. umbellata and $E$. australis) were established and used as possible dietary components in the calculations.

The alkanes $\mathrm{C}_{21}, \mathrm{C}_{23}, \mathrm{C}_{24}, \mathrm{C}_{35}$ and $\mathrm{C}_{36}$ were not used in the diet composition calculations due to their low concentrations in feeds and faeces.

The alkane faecal concentrations were corrected for their incomplete faecal recovery using one set of alkane faecal recovery values obtained by the authors in previous validation studies performed in metabolic cages with goats (Ferreira et al., 2005), sheep (Ferreira et al., 2006) and cattle (Ferreira et al., in press).

\subsubsection{Simulation of feeding selectivity}

For diet composition calculations, seven different levels of feeding selectivity (FS: 0, 5, 15, 30, 60, 90 and $100 \%$ ) were applied to each plant species within each dietary group formed by the cluster analysis, increasing or decreasing in the same extent the proportions of other plant species within each dietary group so that proportions would add up to $100 \%$. The levels of FS tested in this study included total avoidance $(0 \%)$ of each species within each dietary group, selection of each species at $5 \%, 15 \%, 30 \%, 60 \%$ and $90 \%$ of its proportion in the dietary group and total preference for each species $(100 \%)$ within each group. The proportion of the remaining species within the dietary groups was calculated as $(1-\mathrm{FS}) / n$ where FS is the level of feeding selectivity applied and $n$ is the number of the remaining plant species of the dietary group.

\subsection{Statistical analysis}

Statistical analyses were performed using SPSS (SPSS Inc., Ireland) version 11.5 (2002). The groups of the plant species were defined by cluster analysis which was performed in a hierarchical way, using logtransformed concentrations of $n$-alkanes. The plant species were clustered by the Ward linkage method. The groups identified by the cluster analysis were selected on the basis of a strong increment in the proportion of variance accounted by the clusters $(R$ square-ratio between the sum of squares between clusters and the total sum of squares for each of the alkanes used in the analysis). The effect of applying different levels of feeding selectivity $(0,5,15,30,60$, 90 and $100 \%$ ) on a particular plant species within a dietary group on the estimates of the diet composition of goats, sheep and cattle was studied by one-way analysis of variance (ANOVA). When the $F$-test for calculation method was significant $(P<0.05)$, multiple comparisons among means were examined by the Tukey test.

Table 1

\begin{tabular}{|c|c|c|c|c|c|c|c|c|c|c|c|}
\hline & $\mathrm{C}_{25}$ & $\mathrm{C}_{26}$ & $\mathrm{C}_{27}$ & $\mathrm{C}_{28}$ & $\mathrm{C}_{29}$ & $\mathrm{C}_{30}$ & $\mathrm{C}_{31}$ & $\mathrm{C}_{32}$ & $\mathrm{C}_{33}$ & Total & Odd-chain \\
\hline Lolium perenne & 15 & 6 & 35 & 12 & 158 & 17 & 249 & 11 & 122 & 622 & 577 \\
\hline Pseudarrhenatherum longifolium & 17 & 8 & 32 & 12 & 87 & 15 & 297 & 7 & 76 & 550 & 509 \\
\hline Agrostis capillaris & 17 & 5 & 28 & 9 & 59 & 11 & 177 & 5 & 55 & 366 & 336 \\
\hline Calluna vulgaris & 22 & 12 & 76 & 19 & 144 & 33 & 731 & 65 & 567 & 1669 & 1540 \\
\hline Erica cinerea & 16 & 10 & 52 & 19 & 228 & 45 & 1233 & 71 & 602 & 2276 & 2131 \\
\hline Erica umbellata & 35 & 10 & 88 & 20 & 447 & 67 & 1216 & 77 & 482 & 2443 & 2268 \\
\hline Erica australis & 27 & 8 & 76 & 26 & 640 & 63 & 1390 & 63 & 433 & 2725 & 2566 \\
\hline Erica arborea & 104 & 14 & 205 & 38 & 557 & 100 & 1162 & 86 & 286 & 2553 & 2314 \\
\hline Ulex gallii & 8 & 3 & 32 & 10 & 87 & 16 & 300 & 7 & 8 & 470 & 435 \\
\hline
\end{tabular}

Alkane profiles ( $\mathrm{mg} / \mathrm{kg} \mathrm{DM})$ of the plant species encountered in the experimental plot 


\section{Results}

The $n$-alkane profiles of the vegetation components found in the experimental plot (Table 1) are similar to those found in these vegetation species in previous reports (Oliván and Osoro, 1997; Ferreira et al., 2005, 2007). The $n$-alkanes $C_{22}$ and $C_{34}$ are not shown as they were used as internal standards in the alkane analysis. The odd-chain alkanes comprised the highest fraction representing between $90.7 \%$ (E. arborea) and 94.2\% (E. australis) of the total alkane concentration. The individual alkanes present in highest concentrations were $\mathrm{C}_{29}, \mathrm{C}_{31}$ and $\mathrm{C}_{33}$ in all plant species, except for
$U$. gallii which showed higher concentrations of $\mathrm{C}_{27}$ (32 $\mathrm{mg} / \mathrm{kg} \mathrm{DM})$ than $\mathrm{C}_{33}(8 \mathrm{mg} / \mathrm{kg} \mathrm{DM})$. It should be noted the much higher total alkane concentrations of the Ericaceae family (C. vulgaris, E. cinerea, E. umbellata, E. arborea and E. australis) ranging from 1669 to $2725 \mathrm{mg} / \mathrm{kg}$ DM. Contrastingly, A. capillaris presented the lowest total alkane concentration with only $366 \mathrm{mg} /$ kg DM.

In this study, the application of cluster analysis formed four dietary groups. The first group (D1) comprised the three graminaceous species (L. perenne, $P$. longifolium and $A$. capillaris), the second group (D2) included C. vulgaris, E. cinerea, E. umbellata
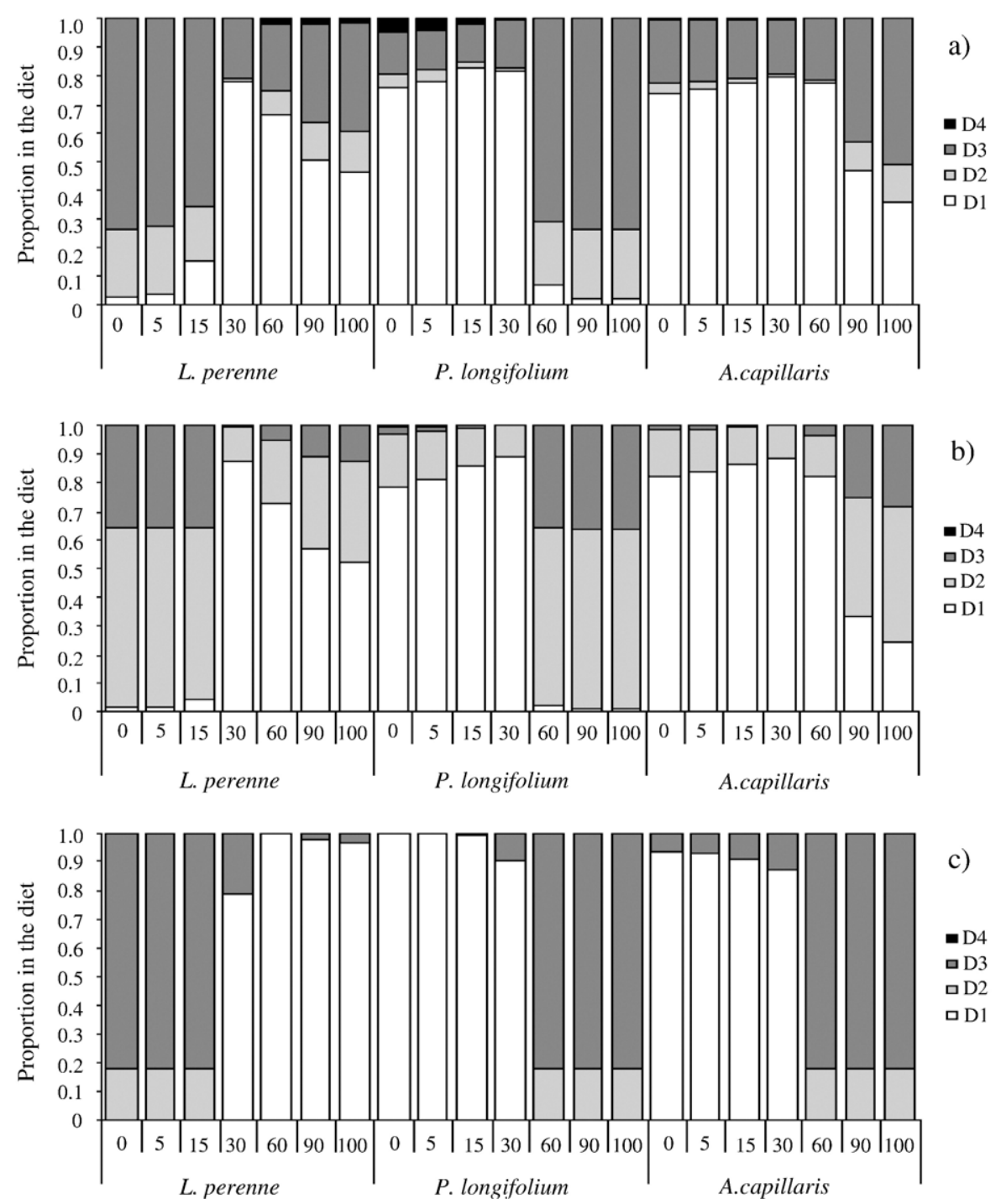

Fig. 1. Variation of diet composition estimates obtained in goats (a), sheep (b) and cattle (c) with the application of different selectivity levels $(0,5,15$, 30, 60, 90 and 100\%) to L. perenne, P. longifolium and A. capillaris within D1 dietary group. 
and E. australis, while E. arborea (D3) and U. gallii (D4) remained as single diet components, due to their distinct $n$-alkane profile.

The effect of applying different selectivity levels $(0$, $5,15,30,60,90$ and $100 \%)$ to each graminaceous species (L. perenne, $P$. longifolium and A. capillaris) within D1 on diet composition estimates is illustrated on Fig. 1.

The FS effect was significant $(P<0.05)$ for all dietary groups in all animal species, except for D4 (U. gallii) when varying the FS of $P$. longifolium (in sheep) and A. capillaris (in goats and sheep). It should be pointed out that the proportion of $U$. gallii was exactly zero regardless of the level of FS of $L$. perenne (sheep and cattle), P. longifolium (cattle) and A. capillaris (cattle) used in D1 group.

As can be observed, the use of different levels of FS of L. perenne in D1 group produced highly variable estimated proportions of D1 (ranging between 0.0300.782), D2 (0.009-0.236) and D3 (E. arborea, 0.208$0.733)$ in the diet of goats. Although the same feature was observed in sheep and cattle, if only the lower levels of FS ( 0,5 and $15 \%$ of $L$. perenne in D1 group) are considered the resultant estimated proportions of all
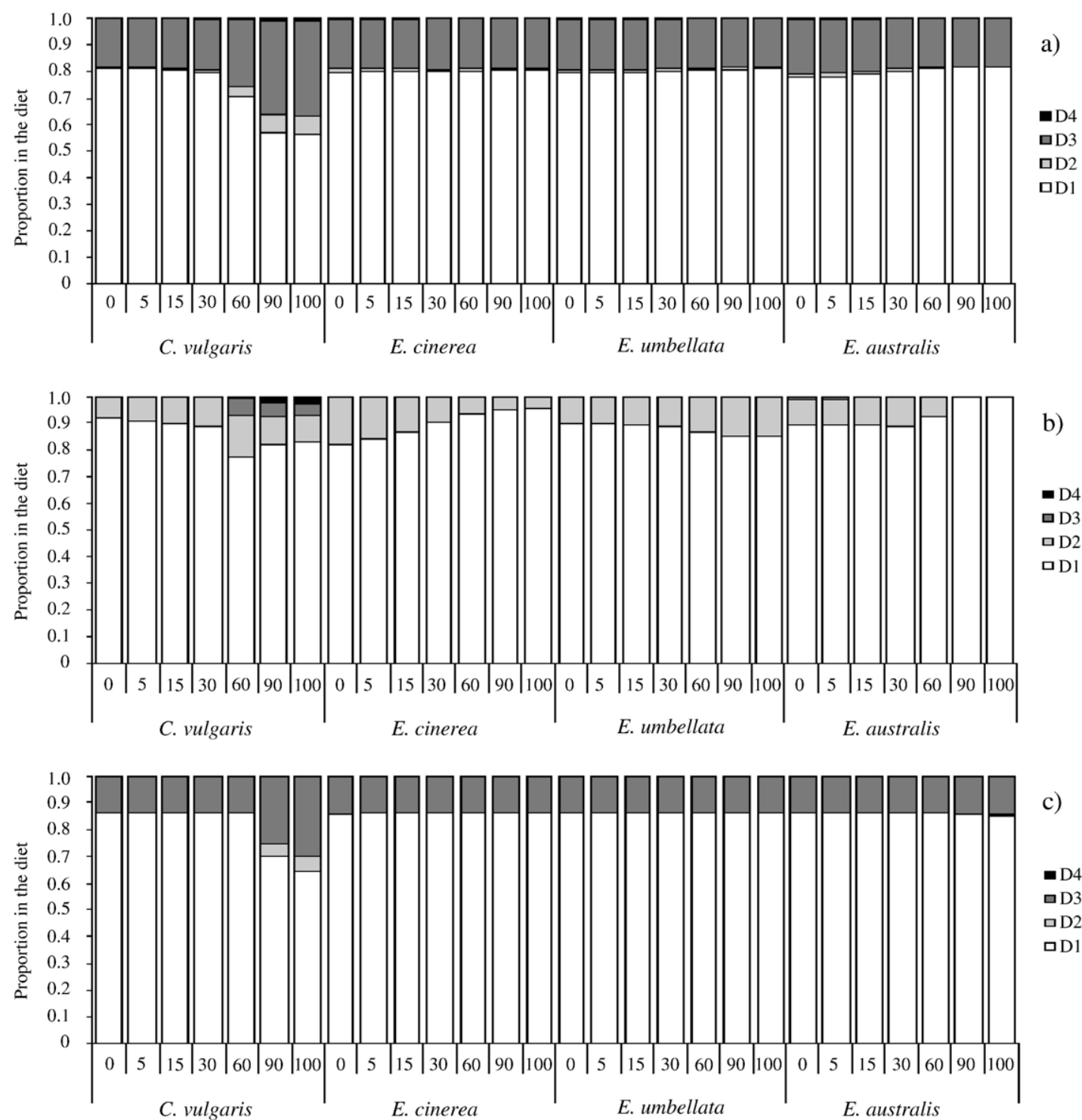

Fig. 2. Variation of diet composition estimates obtained in goats (a), sheep (b) and cattle (c) with the application of different selectivity levels ( 0,5 , 15 , 30, 60, 90 and 100\%) to C. vulgaris, E. cinerea, E. umbellata and E. australis within D2 dietary group. 
dietary groups did not differ significantly. However, an increase of the FS of $L$. perenne in D1 group from 15 to $30 \%$ resulted in the increase of D1 proportion in the diet from 0.042 and 0 to 0.879 and 0.790 in sheep and cattle, respectively. Contrastingly, the same increase resulted in the decrease of D2 proportions from 0.604 and 0.179 to 0.116 and 0 and the decrease of D3 (E. arborea) proportions from 0.354 and 0.821 to 0.005 and 0.210 in sheep and cattle, respectively. However, this increase of L. perenne in D1 (from 15 to 30\%) did not produce significant effects on the estimated proportions of D4 ( $U$. gallii), as it was zero or near zero in all animal species.

In respect with $P$. longifolium and $A$. capillaris, the utilization of different levels of FS on these herbaceous species in D1 group had in cattle similar effects on diet composition estimates than that observed in goats and sheep. When varying their selectivity in the herbage group between 0 and $30 \%$ (P. longifolium) and between 0 and $60 \%$ (A. capillaris) the estimated proportions of all dietary groups did not differ significantly, except for $U$. gallii $(P<0.05)$ when varying the FS of $P$. longifolium. However, the increase from 30 to $60 \%$ and 60 to $90 \%$ in the proportions of $P$. longifolium and A. capillaris, respectively, produced significant $(P<0.05)$ changes in the estimated proportions of the dietary groups, except for the proportions of $\mathrm{D} 4$ (U. gallii) that remained near zero. In the same way, the estimated proportions of dietary components obtained when the selectivity of the same plant species varied from $60-100 \%$ ( $P$. longifolium) and $90-100 \%$ (A. capillaris) did not alter their proportions in the diet of goats and sheep. In cattle, this same lack of effect was observed between $0-15 \%$ and $60-100 \%$ of $P$. longifolium and $A$. capillaris, respectively.

Fig. 2 shows the effect of applying different levels of FS to each heather species $(C$. vulgaris, E. cinerea, E. umbellata and E. australis) within D2 dietary group, on diet composition estimates. There was a significant $(P<0.01)$ effect of varying the FS of $C$. vulgaris on the
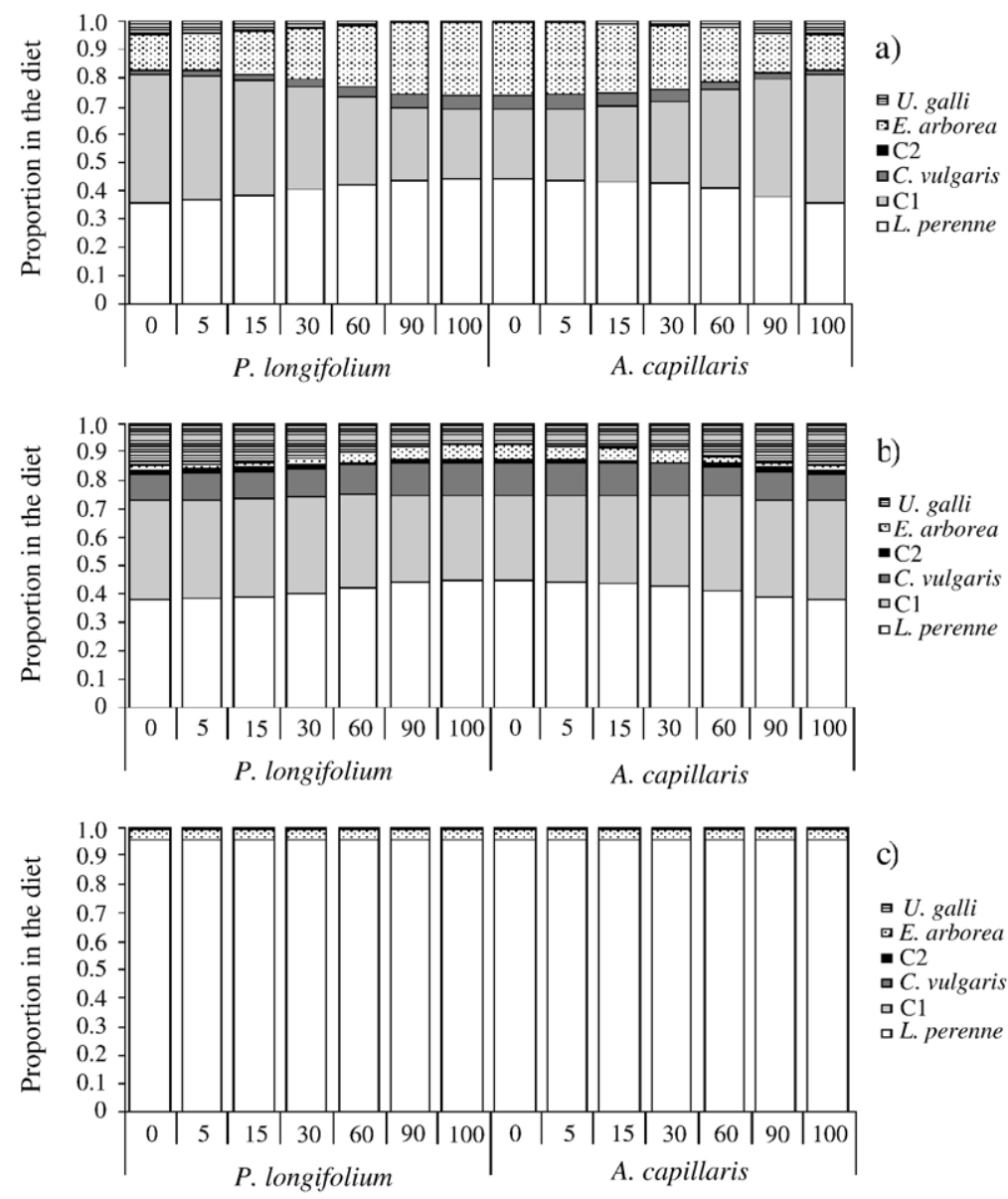

Fig. 3. Variation of diet composition estimates obtained in goats (a), sheep (b) and cattle (c) with the application of different selectivity levels $(0,5$, 15 , 30, 60, 90 and 100\%) to P. longifolium and A. capillaris within C1 dietary group. 
estimated proportions of D1 and D2 in every animal species (goats, sheep and cattle) and D3 (E. arborea) in cattle and on component D2 in the diet of cows when using different levels of FS of E. cinerea. However, if only the data regarding the estimates obtained selecting C. vulgaris from 0 to $60 \%$ in D2 group are considered, the proportions of all dietary groups did not differ in goats and cattle. In the range of $0-60 \%$ of $C$. vulgaris, $5-100 \%$ of E. cinerea, $0-100 \%$ of $E$. umbellata and $0-60 \%$ of $E$. australis within D2 group, the estimated proportions of the dietary groups were numerically equal in the cattle.
The effect of FS was more evident in sheep, being significant $(P<0.05)$ for all dietary groups, except for D3 (E. arborea) and D4 (U. gallii) when varying the FS levels of E. cinerea, D1, D2 and D4 (U. gallii) when varying the FS levels of E. umbellata and D4 (U. gallii) when varying the FS levels of E. australis. However, if only the FS range $0-30 \%$ of $C$. vulgaris and $E$. cinerea, and the FS range $5-60 \%$ of $E$. australis are considered the estimated proportions of all dietary groups did not differ significantly $(P>0.05)$.

As the results obtained through cluster analysis were not able to reduce the FS effect, the hypothesis of
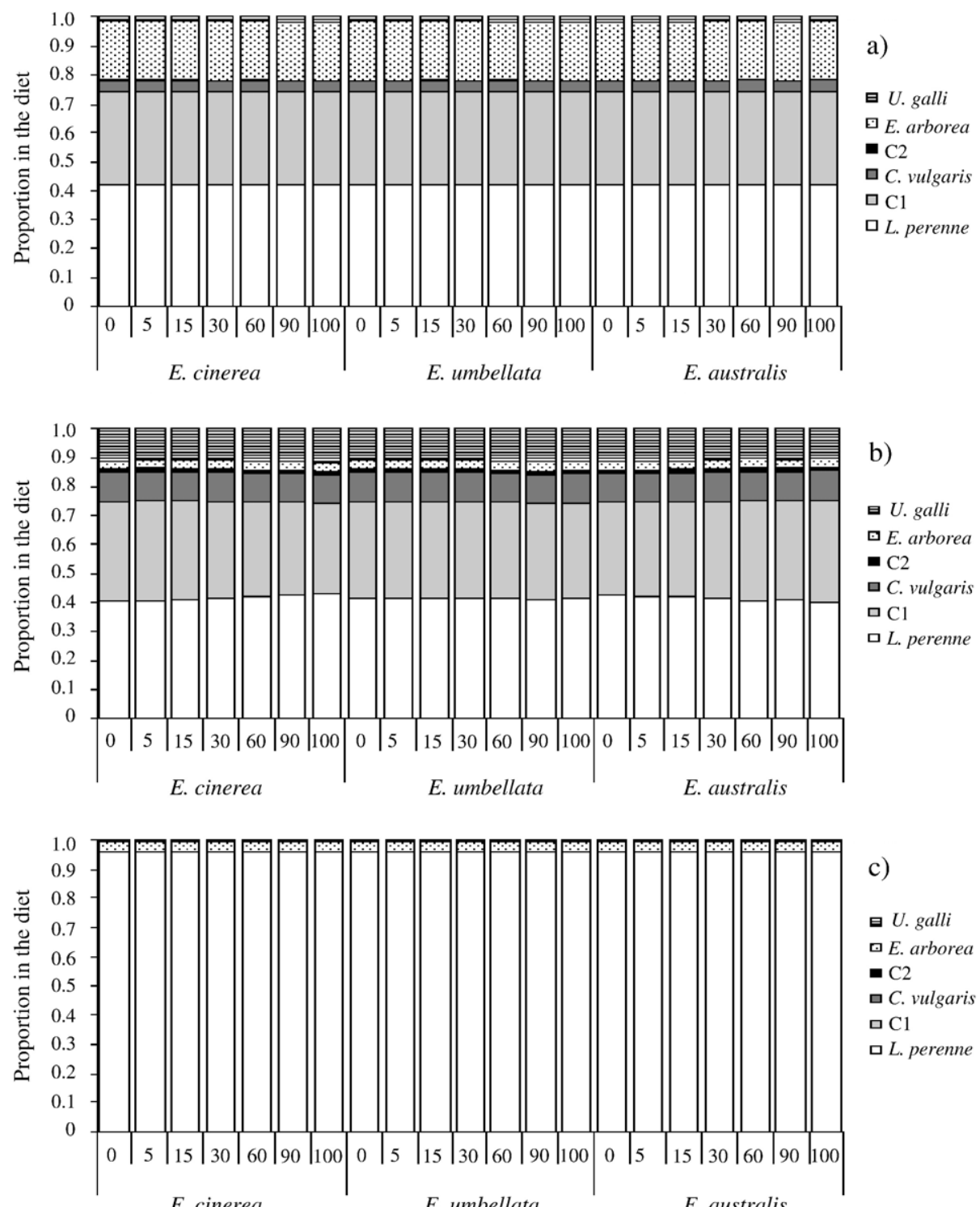

Fig. 4. Variation of diet composition estimates obtained in goats (a), sheep (b) and cattle (c) with the application of different selectivity levels $(0,5,15$, 30, 60, 90 and $100 \%)$ to E. cinerea, E. umbellata and E. australis within C2 dietary group. 
establishing different combinations from D1 dietary group (L. perenne $+P$. longifolium, L. perenne $+A$. capillaris, $P$. longifolium $+A$. capillaris) was tested. The same was performed for $\mathrm{D} 2$ dietary group $(C$. vulgaris $+E$. cinerea + E. umbellata, C. vulgaris $+E$. cinerea $+E$. australis, C. vulgaris $+E$. umbellata $+E$. australis, E. cinerea + E. umbellata + E. australis). A reduction of the FS effect on diet composition estimates was accomplished when considering L. perenne, $\mathrm{C} 1$ (P. longifolium + A. capillaris), C. vulgaris, $\mathrm{C} 2$ (E. cinerea, E. umbellata and E. australis), E. arborea and $U$. gallii as possible diet components (Figs. 3 and 4). In this situation (6 possible diet components), diet composition estimates in cattle were 0.957 (L. perenne), 0 (C1: P. longifolium + A. capillaris $), 0$ (C. vulgaris), 0 (C2: E. cinerea $+E$. umbellata + E. australis), 0.039 (E. arborea) and 0.004 (U. gallii), regardless the levels of FS applied to the plant species comprising $\mathrm{C} 1$ and $\mathrm{C} 2$ dietary groups.

\section{Discussion}

In the present study, the number of plant species available for consumption equals the number of $n$ alkanes (9: $\mathrm{C}_{25}$ to $\mathrm{C}_{33}$ ) selected for the calculations of diet composition, which means that theoretically the alkane markers would be capable of estimating the individual proportions of all plant species in the diet of the animals. However, for the purpose of the present study it was decided to pool plant species into groups according to the similarity in their $n$-alkane profile as suggested by Martins et al. (2002) and Dove and Mayes (2005), in order to evaluate the possible effect of feeding selectivity within the dietary groups.

The results obtained in this study indicate that the effect of FS within a dietary group depends on the plant species that are selected within the dietary group. It is clear that the application of different levels of FS on the herbaceous species comprising the D1 group resulted in different estimates of diet composition, as a result of the modification of the alkane pattern of the dietary group used in the calculations. This effect was not so clear in the heather species that comprised D2 group, especially for goats and cattle.

It should be noted that the dietary groups (D1, D2, D3 and D4) were formed according to the similarity in the alkane profile of the plant species and no differences on its nutritive value were taken into account. This is an important issue to consider in D1 group as the plant species $L$. perenne, $P$. longifolium and A. capillaris present different nutritive values (Celaya et al., 2007). On the contrary, D2 comprised the plant species with similar alkane profile and also nutritive value (Ferreira et al., 2005) and for that reason any selective behaviour between D2 plant species, in contrast to selection within D1, would have little impact on the nutritional status of the animals. Therefore the expression of diet composition in terms of dietary groups rather than individual vegetation species raises a problem: the likely selective behaviour of the animals for a specific plant species within the dietary groups could produce a bias in the diet composition estimates.

Nevertheless, based on the results obtained in this study, it seems that a specific plant species within a dietary group can be selected within a certain range without interfering with the diet composition estimates. For example, when the selectivity of $P$. longifolium and A. capillaris in the D1 group varied between 0 and $30 \%$ and between 0 and $60 \%$, respectively, the estimated proportions of the majority of the dietary groups did not change significantly. This indicates that until a specific weight of a particular plant within a group is used the alkane pattern of the dietary group may not be altered, and consequently there is no effect on the resultant diet composition estimates. These results are consistent with those observed in previous studies performed with goats in metabolic cage studies (Ferreira et al., 2005). In fact, the inclusion of $E$. umbellata, E. cinerea and $C$. vulgaris in the same dietary group (heathers) did not influence negatively the estimates of diet composition. The results suggest that these plant species had a similar $n$-alkane pattern or that one of the plant species was predominant in the dietary group, as heathers represented the field proportion of $E$. umbellata, $E$. cinerea and $C$. vulgaris, at the time the experiment was performed.

Bugalho et al. (2002) evaluated the feeding selectivity effect within an herbage group comprising nineteen herbaceous species on diet composition estimates of red deer selecting on four individual browse species and the herbage group. After weighting the herbaceous species according to their representation in the herbage vegetation, each of 19 species was multiplied by different levels of feeding selectivity $(0,0.5,1.0,1.5$, 2.0 and 3.0), the authors concluded that 0.90 of the 380 simulations were within \pm 0.05 of the values calculated assuming no selection within the herbage group. In our opinion, the great number of plant species that comprised the herbage group and their previous weighting could have diluted the feeding selectivity effect on the estimates of diet composition. It should be pointed out that the results obtained in this study on FS effect can be interpreted as the effect of weighting species within dietary groups. Martins et al. (2002) 
suggest that to obtain accurate estimates of diet composition at the group level, it will be necessary to weight species within dietary groups. Although it is reasonable (based for example on the availability of the plant species in the vegetation cover) to give a higher weight of a more abundant plant species in a dietary group, the results obtained in the present study indicate that this approach should be carried out with caution. Moreover, this weighting procedure based on the vegetation availability can be in opposition with the palatability (nutritive value) of the plant species within the group which have a higher importance in the determination of the animal's selective behaviour (Duncan and Young, 2002; Ginane et al., 2005). For example, Harvey et al. (2000) observed in ewes grazing on perennial ryegrass-white clover pastures a consistent preference for white clover despite its lower availability.

Bugalho et al. (2002) considered that the 3.0 level (ingestion of a species at 3 times the proportion of any other of the 19 species available) was sufficiently high to simulate the possible selectivity within the herbage group. However, in our opinion this level may not have been high enough to produce significant effects on the estimates of diet composition. In our study, for example only when a level of FS of $90 \%$ of A. capillaris was used in the herbage group (D1), the estimates of diet composition in goats and sheep altered significantly, which means that only that level resulted in a deviation of the alkane pattern of the resultant D1 group from the other investigated D1 groups.

The magnitude of the FS effect will depend on the similarity in the alkane profile of the plant species that comprise the dietary group (Bugalho et al., 2004). In our study, cluster analysis did not establish dietary groups with an alkane profile identical enough (especially in the herbage group) to prevent the feeding selectivity effect. This effect could be the result of the cut off point used to define the number of clusters, which may not have been well chosen. Thus, in order to further increase the similarity in the alkane profile within the species comprising the dietary groups D1 and D2 another approach in terms of cluster grouping was attempted. When six clusters were considered, A. capillaris was removed from D1, and D2 was divided in two groups (C. vulgaris $+E$. cinerea and E. umbellata $+E$. australis). Although the utilization of different FS levels was not significant in the group consisting of $E$. umbellata + E. australis, the results were able to demonstrate the persistence of the FS effect on diet composition estimates for the other two groups ( $P$. longifolium $+A$. capillaris and $C$. vulgaris + E. cinerea, data not shown). A significant reduction of the FS effect was achieved when $L$. perenne and $C$. vulgaris were removed from
D1 and D2 and treated as an individual dietary component (Figs. 3 and 4). This could indicate that these plant species did not posses an $n$-alkane profile similar enough to the plant species of D1 (P. longifolium and $A$. capillaris) and D2 (E. cinerea + E. umbellata $+E$. australis), to prevent the effect of FS on the resultant estimates of diet composition.

The effect of FS varied with the animal species, being not so evident in goats and sheep. Thus, it seems that in less selective ruminants, such as cattle, it would be easier to find a correspondence between the alkane profile of faeces and feeds.

\section{Conclusions}

The results from this study suggest that the effect of feeding selectivity for a specific plant species within a dietary group on diet composition estimates depends on the particular species that is selected within the group and on the group itself and could have significant effects on the resultant diet composition estimates. The results obtained by multivariate statistical analysis should be analysed carefully as they could produce dietary groups sensible to FS. A simple exercise like the one made in this study (applying different levels of FS) to the resulting groups can elucidate about the risks of FS in each particular situation. The decrease of feeding selectivity effect on one way can be achieved by the formation of more uniform dietary groups in terms of $n$ alkane profiles and probably in terms of chemical composition and palatability. Therefore where a high number of plant species is available for animal's consumption, some other complementary methods (chemical composition, palatability index, pastoral index, etc.) should be used simultaneously with the alkane method.

\section{Acknowledgments}

LMM Ferreira was funded by the Portuguese Foundation for Science and Technology (Doctoral grant SFRH/BD/16833/2004). The authors would like to thank to the Carbayal Research Station staff for their help in the field work and to M Mocha and MJ Martínez for collaboration in analytical procedures.

\section{References}

Ali, H.A.M., Mayes, R.W., Lamb, C.S., Hector, B.L., Verma, A.K., Ørskov, E.R., 2004. The potential of long-chain fatty alcohols and long-chain fatty acids as diet composition markers: development of methods for quantitative analysis and faecal recoveries of these compounds in sheep fed mixed diets. J. Agric. Sci. 142, 71-78. 
Ali, H.A.M., Mayes, R.W., Hector, B.L., Ørskov, E.R., 2005. Assessment of $n$-alkanes, long-chain fatty alcohols and longchain fatty acids as diet composition markers: the concentrations of these compounds in rangeland species from Sudan. Anim. Feed Sci. Technol. 121, 257-271.

Brosh, A., Henkin, Z., Rothman, S.J., Aharoni, Y., Orlov, A., Arieli, A., 2003. Effects of faecal $n$-alkane recovery in estimates of diet composition. J. Agric. Sci. 140, 93-100.

Bugalho, M., Mayes, R.W., Milne, J.A., 2002. The effects of feeding selectivity on the estimation of diet composition using the $n$-alkane technique. Grass Forage Sci. 57, 224-231.

Bugalho, M.N., Dove, H., Kelman, W., Wood, J.T., Mayes, R.W., 2004. Plant wax alkanes and alcohols as herbivore diet composition markers. J. Range Manag. 57, 259-268.

Celaya, R., Oliván, M., Ferreira, L.M.M., Martínez, A., Garcia, U., Osoro, K., 2007. Comparison of grazing behaviour, dietary overlap and performance in non-lactating domestic ruminants grazing on marginal heathland areas. Livest. Prod. Sci. 106, 271-281.

Dove, H., Mayes, R.W., 2005. Using $n$-alkanes and other plant wax components to estimate intake, digestibility and diet composition of grazing / browsing sheep and goats. Small Rumin. Res. 59, 123-139.

Dove, H., Mayes, R.W., Freer, M., 1996. Effects of species, plant part, and plant age on the $n$-alkane concentrations in the cuticular wax of pasture plants. Aust. J. Agric. Res. 47, 1333-1347.

Duncan, A.J., Young, S.A., 2002. Can goats learn about foods through conditioned food aversions and preferences when multiple food options are simultaneously available? J. Anim. Sci. 80, 2091-2098.

Ferreira, L.M.M., Oliván, M., Garcia, U., Rodrigues, M.A.M., Osoro, K., 2005. Validation of the alkane technique to estimate diet selection of goats grazing heather-gorse vegetation communities. J. Sci. Food Agric. 85, 1636-1646.

Ferreira, L.M.M., Oliván, M., Celaya, R., Garcia, U., Rodrigues, M.A.M., Osoro, K., 2007. The use of the alkane technique to estimate diet selection of sheep grazing grass-clover/heathergorse vegetation communities. J. Sci. Food Agric. 87, 274-285.

Ferreira, L.M.M., Garcia, U., Rodrigues, M.A.M., Celaya, R., Dias-daSilva, A., Osoro, K., in press. The application of the $n$-alkane technique for estimating the composition of diets consumed by equines and cattle feeding on upland vegetation communities. Anim. Feed Sci. Tech. doi: 10.1016/j.anifeedsci.2006.11.007.
Ginane, C., Duncan, A.J., Elston, D.A., Young, S.A., Gordon, I.J., 2005. Herbivore diet selection in response to simulated variation in nutrient rewards and plant secondary compounds. Anim. Behav. 69, 541-550.

Harvey, A., Parsons, A.J., Rook, A.J., Penning, P.D., Orr, R.J., 2000. Dietary preferences of sheep for perennial ryegrass and white clover at contrasting sward surface heights. Grass Forage Sci. 55, 242-252.

Hoebee, S.E., Dove, H., Officer, D.I., 1998. Using plant wax alkanes to estimate the species composition of sub-tropical grass mixtures. Anim. Prod. Aust. Soc. Anim. Prod. Bienn.Conf. 22, 364.

Kelman, W., Bugalho, M., Dove, H., 2003. Cuticular wax alkanes and alcohols used as markers to estimate diet composition of sheep (Ovis aries). Biochem. Syst. Ecol. 31, 919-927.

Lewis, R.M., Magadlela, A.M., Jessop, N.S., Emmans, G.C., 2003. The ability of the $n$-alkane technique to estimate intake and diet choice of sheep. Anim. Sci. 77, 319-327.

Martins, H., Elston, D.A., Mayes, R.W., Milne, J.A., 2002. Assessment of the use of $n$-alkanes as markers to describe the complex diets of herbivores. J. Agric. Sci. 138, 425-434.

Mayes, R.W., Lamb, C.S., Colgrove, P.M., 1986. The use of dosed and herbage $n$-alkanes as markers for the determination of herbage intake. J. Agric. Sci. 107, 161-170.

Oliván, M., Osoro, K., 1997. Utilización de la técnica de los $n$-alcanos en estudios de ingestión y selección de dieta de los rumiantes en pastoreo: Revisión. Inf. Téc. Econ. Agrar. 93A, 193-208.

Oliván, M., Osoro, K., 1999. Effect of temperature on alkane extraction from faeces and herbage. J. Agric. Sci. 132, 305-312.

Oliván, M., Dove, H., Mayes, R.W., Hoebee, S.E., 1999. Recent developments in the use of alkanes and other plant wax components to estimate intake and diet composition in herbivores. Rev. Port. Zootec. VI (1), 1-26.

Salt, C.A., Mayes, R.W., Colgrove, P.M., Lamb, C.S., 1994. The effects of season and diet composition on the radiocaesium intake by sheep grazing on heather moorland. J. Appl. Ecol. 31, 125-136. SPSS 11.5., 2002. Guía breve. SPSS Inc., Ireland.

Valiente, O.L., Delgado, P., de Vega, A., Guada, J.A., 2003. Validation of the $n$-alkane technique to estimate intake, digestibility, and diet composition in sheep consuming mixed grain:roughage diets. Aust. J. Agric. Res. 54, 693-702. 